\title{
Behavior of Reinforced Soil Slope by Finite Element Methods
}

\author{
Itthinon Thongpetch \\ Thammasat Student \\ Department of Civil Engineering \\ Thammasat University \\ Bangkok, Thailand
}

\author{
Weeraya Chimoye \\ Associate Professor \\ Department of Civil Engineering \\ Thammasat University \\ Bangkok, Thailand
}

\begin{abstract}
This article presents the behavior of reinforced soil slope by finite element method. The model of reinforced soil slope is assumed to be 60 degree steep and over firm soil foundation. The parametric studies are carried out to investigate the effect of the height of reinforced soil slope $(\mathrm{H})$, interface shear strength of geosynthetic and backfill soil, (R-Int) and internal friction angle of backfill soil, $(\phi)$ on the safety factor (FS) and maximum total displacement (TD). It was found that R-Int and internal friction angle are main factors on the factors of safety and total displacement of the reinforced soil slope. When the R-Int and internal friction angle increased, the factor of safety of the reinforced soil slope increased. In the opposite way, the total displacement decreased with the increasing of $\mathbf{R}$ Int and internal friction angle. For the height of reinforced soil slope had little effect through the factor of safety but affected the maximum total displacement correspond with factor of safety. The maximum total displacement increased with the increasing of the height of reinforced soil slope when the factor of safety closed to one.
\end{abstract}

Keywords-Component; Reinforced Soil Slope; Internal Friction Angle; Geosynthetics; Finite Element Method

\section{INTRODUCTION}

Currently, the construction work related to geotechnical engineering has played a very important role. Especially the work related to the soil work of the project such as backfill soil work, road construction, high backfill embankment and side slope protection. The constrains of these projects are the right-of-way and the steep of the site slope in order to safe the area of the right-of-way and backfill material. Normally, the design slope angle is steeper than normal varied from $60-80$ degrees then caused the slope stability problem. The reinforced soil slope technique by using geogrid or geotextiles is the most popular method to used in these cases since it can safe up to $50 \%$ about cost of construction compared with concrete gravity retaining wall or anchored sheet pile wall [1]-[2]. Usually the cost of construction mainly depend on the cost of backfill material and transpotation cost, cost of the reinforced material and the construction process. If the design slope angel is the same then the cost of the backfill and transpotation cost are the same. The discrepancies are the cost of reinforce material material which geosynthetic is quite lower than reinforced concrete and steel sheet pile and the cost of construction process. The construction of reinforced soil slope is simply, quick and labor incentive compared with others. It can be built in several stages and does not demand skilled labor. The process involves erecting a layer of facing elements connected to the reinforcement, placing the backfill and compacting adequately. The construction process can be repeated until the entire structure reaches the require height. Another advantage is the reinforced soil slope can be constructed together with backfill soil work but, for the concrete gravity retaining wall or anchored sheet pile wall system, the retaining structure has to be constructed first then the compaction of backfill can be continued after that. So it caused time consumed during this construction part. Moreover for the reinforced soil slope, the residual soil on site can be used as backfill material which can safe the transportation cost while for other systems cannot be used [3]. In Thailand, the ground improvement technique with reinforced soil slope method is used for many types of the project such as high embankment backfill, road construction backfill, side slope repair and etc but still has a little of research to study about its behavior. In this research, the behavior of the reinforced soil slope is studied by Finite Element Method. The effect of the slope height $(\mathrm{H})$, internal friction angle $(\phi)$ and interface shear strength of geosynthetics and soil (R-Int.) on the behavior of reinforced soil slope are reported.

\section{MODEl OF REINFORCED SOIL SLOPE}

The model of reinforced soil slope has 60 degree of slope angle, $30 \mathrm{~m}$. width, and for the foundation, it has $70 \mathrm{~m}$. width and $30 \mathrm{~m}$. depth in order to neglect the effect of side boundary when the failure of the reinforced soil slope occurred as shown in Fig. 1 (a) [4]. The reinforced soil slope is modelled using the finite element analysis program PLAXIS-2D [5] The finite element model of reinforced soil slope used in this analysis is plain strain condition. As a plain strain condition is used for geometries with a uniform cross section and corresponding stress and loading scheme over a certain length perpendicular to the cross section ( $\mathrm{z}$ direction). The displacement and strain in z-direction are assumed to be zero. However, the normal stress in $\mathrm{z}$ direction are fully taken into account. The model of backfill soil and foundation soil use drain condition and undrain condition with perfectly - plastics Mohr Coulomb failure, respectively. The Mohr Coulomb failure method can determine the factor of safety analysis of the reinforced soil slope by Phi-C reduction function. In the Phi-C reduction analysis, the strength parameter $\tan \phi$ and $\mathrm{c}$ 
of the soil are successively adjust until the reinforced soil slope approaches the verge of failure. The finite element mesh used for the numerical simulations is shown in Fig. 1 (b). The mesh is made up of very fine triangular continuum elements with 15 nodes and will able to simulate the shear strength of soil mass in PLAXIS-2D software. The mesh is created automaticly highest mesh resolution for finite element analysis in order to reduce effect and provide the most accurate answer. The reinforcement is high-tenacity of extensible geosynthetic material and axial tensile stiffness is $10 \%$ strain [6]. It was modeled as an elastic model without compressive strength and bending moment. The simulation is combine these elements with interface to the model of soil interaction. In the PLAXIS-2D software. In addition, the interface strength behavior of soil to reinforcement depends on the friction angle of backfill soil and bearing resistance of the reinforcement to soil as well as the shear resistance. The interface of soil to reinforcement behavior is modeled by elastic perfectly-plastics model. Whereby the strength properties of soil and axial tensile stuffiness of reinforcement is linked by interface model. The interface surrounding of soil and reinforcement is shown in Fig.1 (c). Finally, the facing system of reinforced soil slope used the reinforcement material wrap around system, the vertical spacing is $0.50 \mathrm{~m}$. and warp around length is $1.50 \mathrm{~m}$ for each layers respectively, In the PLAXIS-2D software, the facing system is modeled by elastic model as same as properties of reinforcement material.

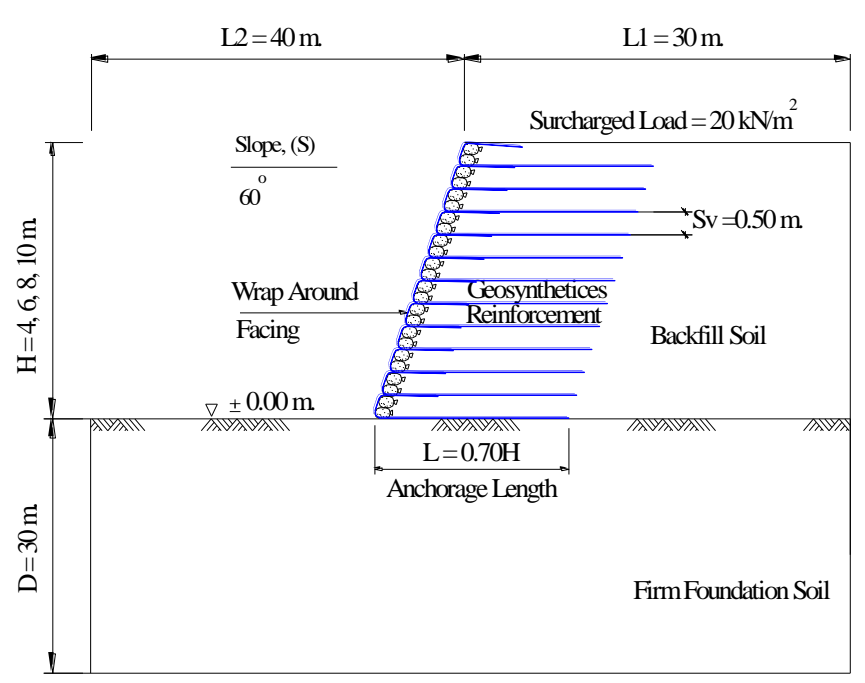

(a) Cross-section of reinforced soil slope (RSS)

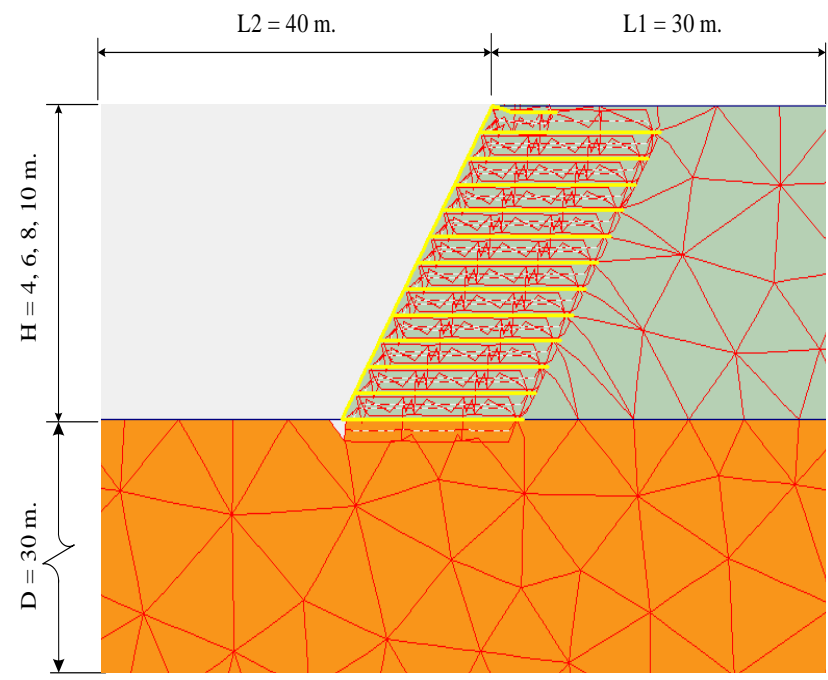

(b) Cross-section of finite element methods (FEM)

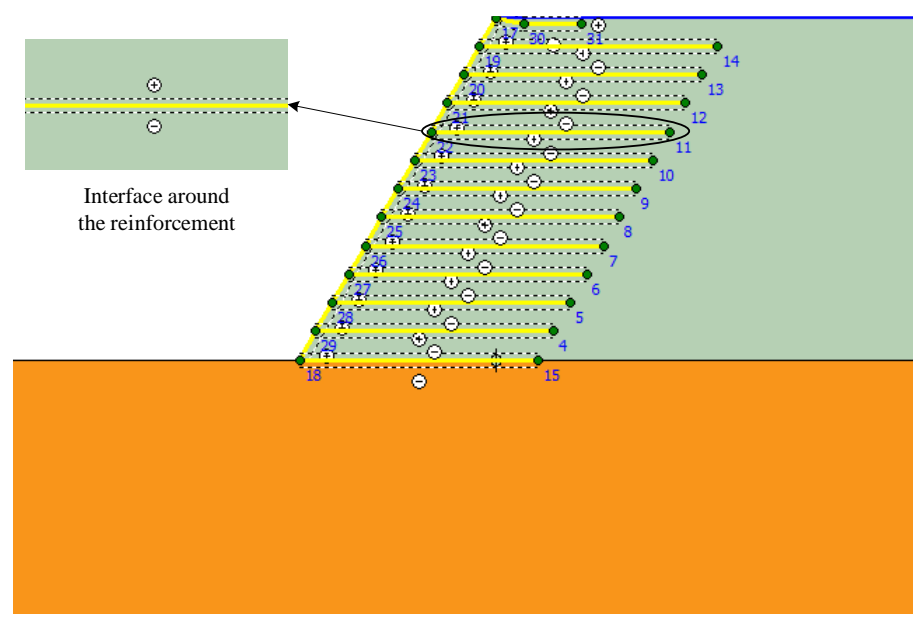

(c) Cross-section of interface soil to reinforcement interaction by finite element methods (FEM)

Fig. 1: Reinforced soil slope for Modeling 


\section{MATERIALS AND Methodology}

The properties of soil and reinforcement are tabulated in Table I. The anchorage length, $\mathrm{L}=0.70 \mathrm{H}$ and the tensile stiffness of reinforcement material $=1,000 \mathrm{kN} / \mathrm{m}$ are modeled. The influence of several parameters (Height of slope, interface shear strength, internal friction angle) on the behavior of the reinforced soil slope is studied. The height of slope is varied 4, 6, 8 and $10 \mathrm{~m}$, the interface shear strength is varied $0.5,0.7$ and 0.9 and the internal friction angle of the backfill soil is varied $25,30,35$ and 40 degrees. The behaviors of the reinforced soil slope are reported in term of the failure behavior, factor of safety (FS) and the total displacement (TD).

TABLE I. GEOMETRIC MODEL AND PARAMETRIC STUDY OF REINFORCED SOIL SLOPE

\begin{tabular}{|c|c|c|}
\hline DISCRIPTIONS & UNITS & FOR RESEARCH \\
\hline 1. Height & $\mathrm{m}$. & $4,6,8,10$ \\
\hline 2. Interface Shear strength & - & $0.50,0.70,0.90$ \\
\hline 3. Internal Friction Angle of Backfill Soil & Degree & $25,30,35,40$ \\
\hline 4. Anchorage Length of Geogrid & - & $0.70 \mathrm{H}$ \\
\hline 5. Slope angle & Degree & 60 \\
\hline 6. Width of Embankment & $\mathrm{m}$. & 30 \\
\hline 7. Width of Foundation Soil & $\mathrm{m}$. & 70 \\
\hline 8. Depth of Foundation Soil & $\mathrm{m}$. & 30 \\
\hline 9. Surcharged load & $\mathrm{kN} / \mathrm{m}^{2}$ & 20 \\
\hline 10. Unsaturated unit weight of Backfill Soil & $\mathrm{kN} / \mathrm{m}^{3}$ & 20 \\
\hline 11. Cohesion of Backfill Soil & $\mathrm{kN} / \mathrm{m}^{2}$ & 5 \\
\hline 12. Model Perfect-Plasticity & - & Mohr-Columb \\
\hline 13. Model Type of Backfill Soil & - & Drained \\
\hline 14. Poisson's Ratio of Backfill Soil & - & 0.30 \\
\hline 15. Elastic modulus of Backfill Soil & $\mathrm{kN} / \mathrm{m}^{2}$ & 766(SPT) \\
\hline 16. Saturated unit weight of Foundation Soil & $\mathrm{kN} / \mathrm{m}^{3}$ & 21 \\
\hline 17. Model Type of Foundation Soil & - & Undrained \\
\hline 18. Model of Geogrid & - & Elastic \\
\hline 19. Tensile Stiffness of Geogrid & $\mathrm{kN} / \mathrm{m}$ & 1,000 \\
\hline 20. Vertical spacing of Geogrid & $\mathrm{m}$. & 0.50 \\
\hline 21. Facing types & - & Wrap Around Type \\
\hline 22. Ground water leveling & $\mathrm{m}$. & 0+0.00 (Top Foundation Soil) \\
\hline
\end{tabular}

\section{RESUlTS AND DisCUSSIONS}

The results of factor of safety and total displacement of the reinforced soil slope that modelled in PLAXIS are summarized in Table II.

\section{Influence of height of reinforced soil slope.}

The factor of safety of the reinforced soil slope is almost constant with the increasing of the height of the reinforced soil slope as shown in Fig. 2 when the R-interface equal to 0.7. But the factor of safety is different with the internal friction angle of backfill soil, when the internal friction angle is small then the factor of safety is closed to one. This caused the influence of height of reinforced soil slope on the total displacement is separated in two ways as shown in Fig. 3. When the internal friction is small, the factor of safety is less than 1.17 , so the total displacement increased with the increasing of height of reinforced soil slope. But when the internal friction angle is high (more than $30^{\circ}$ ), the factor of safety is more than 1.38 , the total displacement is almost constant with the increasing of height of reinforce soil slope. This means that the height of reinforced soil slope is not independent parameters that affects to the factor of safety and the maximum total displacement. Due to the geosynthetics reinforcement that insert into the embankment is proportion with the height of reinforced soil slope and will increased shear strength and passive resistance of reinforced soil slope [7] and reduce the force on soil mass [8]. So that when the internal friction angle is high, the factor of safety higher than 1.3 , then the height of the reinforce soil slope did not affect the factor of safety and the maximum total displacement. In the opposite way, when the internal friction angle is low, the factor of safety closed to one, the height of the reinforce soil slope did not affect the factor of safety but highly affect to the maximum total displacement. 


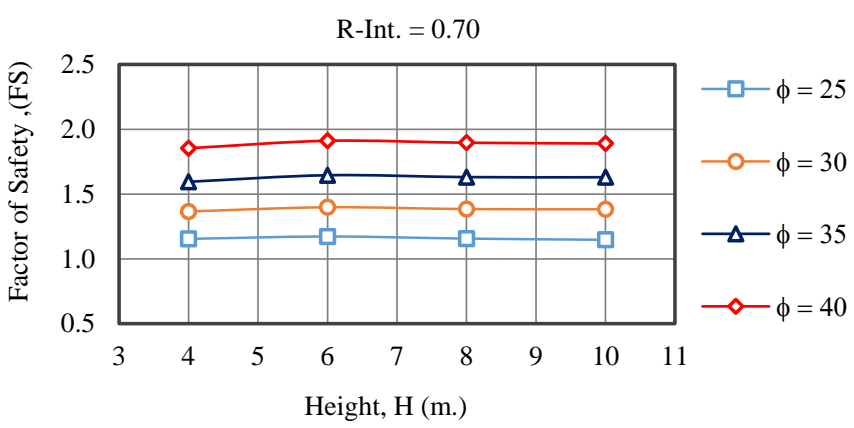

Fig. 2: Relationship between FS and $\mathrm{H}$

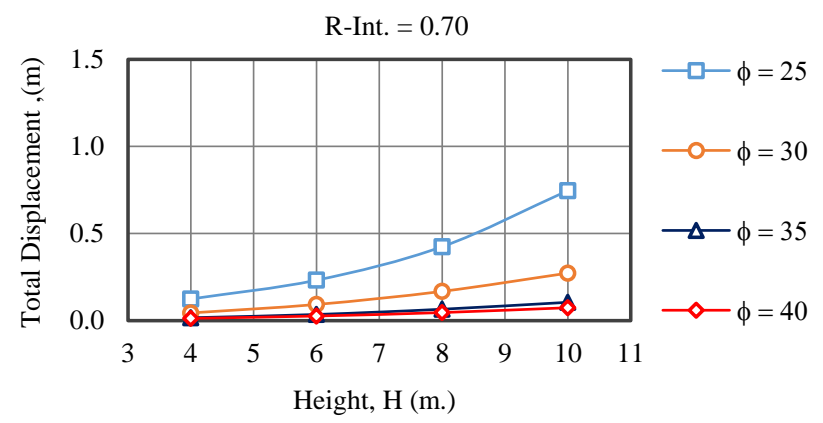

Fig. 3: Relationship between TD and $\mathrm{H}$

TABLE II. FACTOR OF SAFETY AND TOTAL DISPLEACEMENT WITH VAIRUOS H, $\phi$ AND R-Int.

\begin{tabular}{|c|c|c|c|c|c|c|c|c|c|c|}
\hline \multirow{2}{*}{ NO. } & HEIGHT & INTERFACE SHEAR & \multicolumn{3}{|c|}{$\begin{array}{c}\text { FEM-FACTOR OF SAFETY (-) } \\
\text { SHRENGTH, (R-Int.) }\end{array}$} & \multicolumn{3}{|c|}{ FEM-TOTAL DISPLACEMENT (m.) } \\
\cline { 4 - 10 }- & $\mathrm{H}$. & - & $\phi=25$ & $\phi=30$ & $\phi=35$ & $\phi=40$ & $\phi=25$ & $\phi=30$ & $\phi=35$ & $\phi=40$ \\
\hline 1 & 4 & 0.50 & 1.034 & 1.218 & 1.418 & 1.629 & 0.176 & 0.061 & 0.026 & 0.018 \\
2 & 6 & 0.50 & 1.012 & 1.204 & 1.387 & 1.609 & 0.454 & 0.142 & 0.050 & 0.038 \\
3 & 8 & 0.50 & 0.993 & 1.184 & 1.386 & 1.609 & 0.739 & 0.262 & 0.094 & 0.069 \\
4 & 10 & 0.50 & 0.978 & 1.171 & 1.376 & 1.596 & 1.310 & 0.413 & 0.149 & 0.113 \\
5 & 4 & 0.70 & 1.155 & 1.366 & 1.596 & 1.854 & 0.125 & 0.044 & 0.017 & 0.013 \\
6 & 6 & 0.70 & 1.173 & 1.399 & 1.645 & 1.912 & 0.233 & 0.093 & 0.035 & 0.027 \\
7 & 8 & 0.70 & 1.157 & 1.385 & 1.631 & 1.897 & 0.425 & 0.168 & 0.065 & 0.047 \\
8 & 10 & 0.70 & 1.148 & 1.383 & 1.630 & 1.891 & 0.747 & 0.273 & 0.105 & 0.074 \\
9 & 4 & 0.90 & 1.248 & 1.484 & 1.744 & 2.034 & 0.099 & 0.034 & 0.015 & 0.012 \\
10 & 6 & 0.90 & 1.282 & 1.539 & 1.818 & 2.132 & 0.218 & 0.077 & 0.030 & 0.023 \\
11 & 8 & 0.90 & 1.272 & 1.534 & 1.805 & 2.135 & 0.405 & 0.140 & 0.054 & 0.039 \\
12 & 10 & 0.90 & 1.273 & 1.541 & 1.797 & 2.108 & 0.612 & 0.219 & 0.084 & 0.060 \\
\hline
\end{tabular}

Influence of the internal friction angle.

Fig. 4 shows the relationship between internal friction angle of the backfill soil and the factor of safety of the reinforced soil slope with different height of reinforced soil slope and constant R-interface (0.7). It can be seen that the factor of safety increased with the increasing of the internal friction angle. The factor of safety is almost the same without effect of the height of reinforced soil slope. This means the internal friction angle of the backfill soil is the principle parameter on the reinforced soil slope [9] by increased the interface shear strength of geosynthetics and soil. The same relationship also found in the case of maximum total displacement. The maximum total displacement decreased with the increasing with of the internal friction angle of the backfill soil as shown in Fig. 5 .

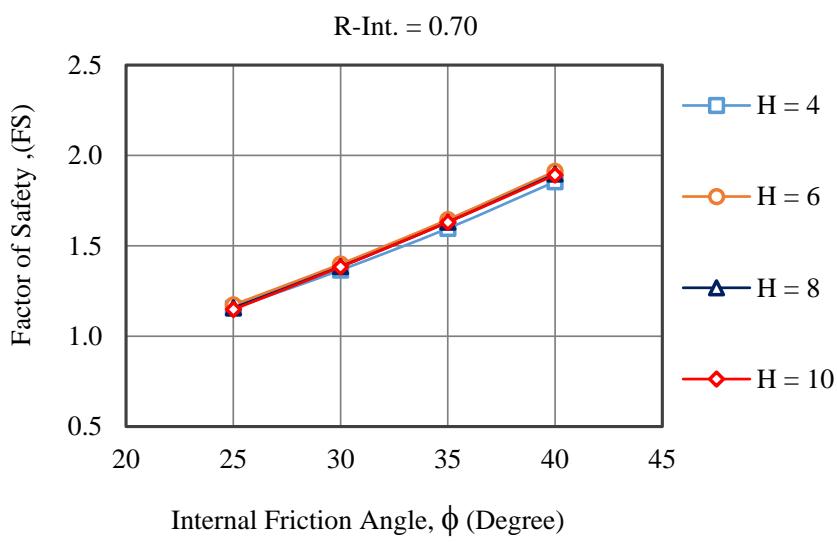

Fig. 4: Relationship between FS and $\phi$

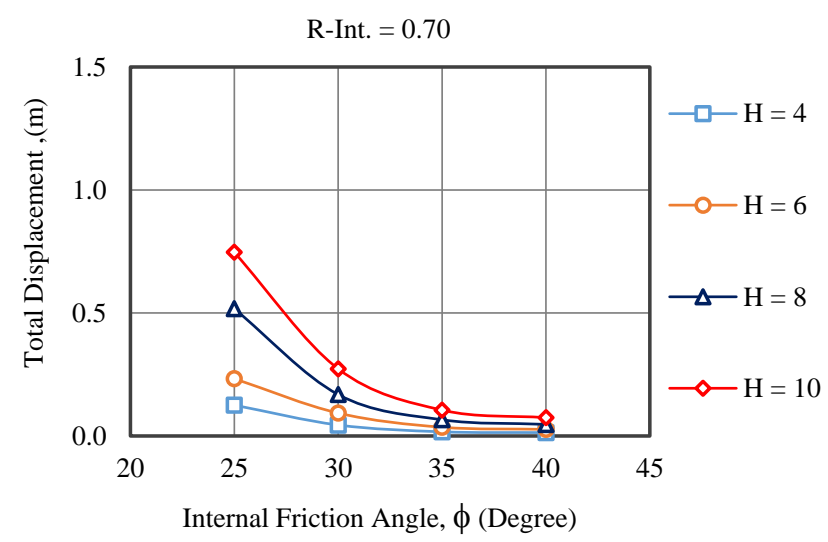

Fig. 5: Relationship between TD and $\phi$ 
When the internal friction angle is equal to 35 and 40 degree the maximum total displacement is small less than 0.1 $\mathrm{m}$ which related to the ratio of factor of safety that more than 1.5. In case of the internal friction angle is equal to 25 and 30 degree the maximum total displacement increased rapidly especially when the height of the reinforced soil slope is high $(\mathrm{H}=10 \mathrm{~m})$ since the factor of safety is closed to one and the reinforced soil slope nearly failure.

\section{Influence of the interface shear strength (R-Interface)}

In PLAXIS-2D, the friction between soil mass and geosynthetic can be modeled by using R-Interface, it is the ratio of the friction that compared with the internal friction angle of backfill soil. If the R-interface equal to one means the friction between soil and geosynthetic is the same as the friction in the soil mass, so that in this study the R-interface is varied about $0.5,0.7$ and 0.9 . Fig. 6 shows the relationship between the R-Interface and factor of safety when the internal friction angle of backfill soil varied from $25-40$ degrees and the height of the reinforced soil slop equal to $8.0 \mathrm{~m}$. It can be found that the factor of safety increased with the increasing of R-interface for all cases of internal friction angle. Due to the R-Int value is improvised the shear strength at the surface between geosynthetic and soil which depend on the type, size and shape of geosynthetic material and type backfill soil [10][11]. In the opposite way, the maximum total displacement decreased with the increasing of the R-interface especially when the internal friction angle of backfill soil is low $\left(25^{\circ}\right)$ since the magnitude of the maximum total displacement is high. But when the internal friction angle is high (more than $30^{\circ}$ ), the maximum total displacement is almost constant with the increasing of the R-interface.

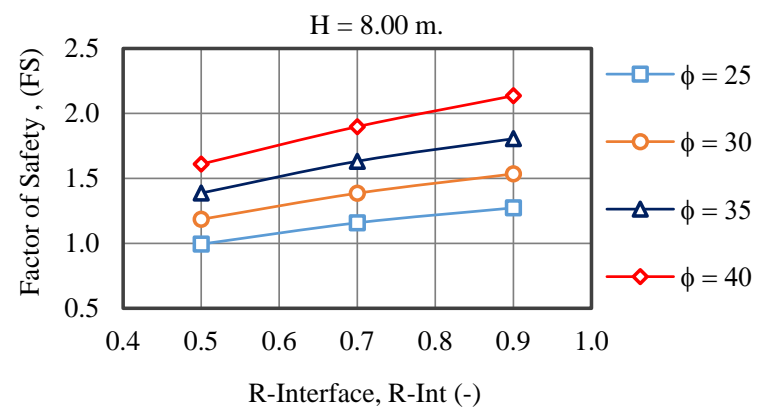

Fig. 6: Relationship between FS and R-Int

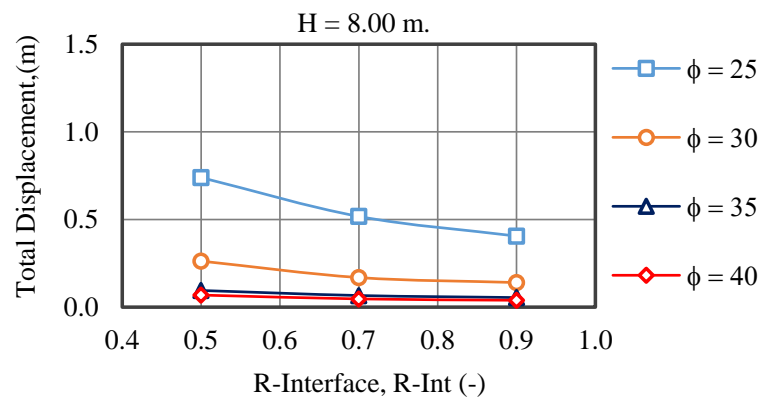

Fig. 7: Relationship between TD and R-Int

\section{CONCLUSIONS}

The behavior of reinforced soil slope in term of factor of safety and the maximum total displacement is studied with some parameters by PLAXIS-2D. The parametric studies in this research are the internal friction angle of backfill soil, the interface shear strength and the height of the reinforced soil slope. From the results, it can be concluded that the internal friction angle of the backfill soil is the significant parameter that affects the factor of safety and the maximum total displacement of the reinforced soil slope. Whereas the interface shear strength is the parameters that compensated with the internal friction angle since it is the ratio of the friction that compared with internal friction angle. For the height of reinforced soil slope, it does not affect to the factor of safety but it indirectly affects to the maximum total displacement. The maximum total displacement increased with the increasing of the height of reinforced soil slope when the internal friction is small since the factor of safety closed to one but when the internal friction is high the maximum total displacement is almost constant with height of reinforced soil slope.

\section{ACKNOWLEDGMENT}

Author would like to thank Thammasat University for providing PLAXIS-2D to be analyzed in this research until accomplished well

\section{REFERENCES}

[1] Cheney, R.S., (1990). Selection of retaining structures: The owner's perspective, proceeding ASCE Conference Design and Performance of Earth Retaining Structures, Geotechnical Special Publish 25, Ithaca, New York, pp-52-65.

[2] Elias, V., Christopher, B.R., and Berg, R.R., (2001), Mechanically stabilized earth walls and reinforced soil slopes, design and construction guidelines. Publication No. FHWA-NHI-00-043, Federal Highway Administration (FHWA), Washington (DC).

[3] Wu, J.T.H., (1994), Design and Construction of Low Cost Retaining Walls. Colorado Department of Transportation Publication No. CTI-UCD-1-94,152p.

[4] Fethi Azizi, (2000), Applied Analysis in Geotechnics, Publication by E \& FN Spon 11 New Fetter Lane, London EC4P 4EE, pp-738-739.

[5] Brinkgreve, R.B.J, (2002), PLAXIS-2D-Version 8, Delft University of Technology \& PLAXIS.b.v., The Netherlands, Published and distributed by: A.A. Balkema Publisher's, a Member of Swets \& Zeitlinger publishers, ISBN 9058095088.

[6] British Standard Institution, (1995), Code of practice for Strengthened/reinforced soils and other fills, BS8006, BSI, London, $207 \mathrm{p}$.

[7] Koerner, Robert M., (1997), Designing with geosynthetices $4^{\text {th }}$ Edition, by Prentice-Hall, Inc., pp-325

[8] Liu Chia-Nan, Ho Yu-Hsien and Huang Jian-Wen (2009), Large Scale direct shear tests of soil/PET Yarn geogrid interfaces. In: Geotextiles and Geomembranes, 27(4), pp-19-30

[9] R. A. Jewell, Exxon Chemical Geopolymers Ltd, (1989) Designing for Soil Reinforcement, Exxon Chemical Geopolymers Limited, pp-4-9

[10] Palmeira, E.M., (2009), Soil-geosynthetics interaction: Modeling and analysis. In: Geotextiles and Geomembranes, pp 368-390.

[11]Tuna, S.C. and Altun, S., (2012), Mechanical behavior of soilgeotextiles interface. In: Scientia Iranica, 19(4), pp-1044-1051 